\title{
A Comparative Study of Different Recovery Programmes on Blood Lactate Removal
}

\author{
Suranjita Khan $^{1}$, Dr. Nita Bandyopadhyay ${ }^{2}$ \\ ${ }^{1} \mathrm{PhD}$ Scholar, Department of Physical Education, University of Kalyani, West Bengal, India \\ ${ }^{2}$ Assistant Professor, Department of Physical Education, University of Kalyani, West Bengal, India
}

\begin{abstract}
The purpose of this study was to compare the clearance of accumulated blood lactate during recovery. Sixty university level male sportsperson (Hockey:20, Handball:20 and Football:20) from Punjabi University. Patiala, India, volunteered as subjects. Their age ranged between 18-25 years. The subjects were equally distributed in four experimental groups taking five subjects from each discipline. Fifteen subjects in each group. Group I attended stretching exercise, Group II attended slow cycling, Group III attended autogenic muscle relaxation and Group IV attended progressive muscle relaxation. The blood lactate was measured on day one and after twenty-one days of the application of different treatments. Analysis of Covariance was used to assess differences among the experimental groups. Further the Bonferroni test was applied to determine which of the paired mean had significant differences. The relative reduction in blood lactate concentration was significantly greater in Group I i.e., stretching exercise (p<0.05) as compared to other groups.
\end{abstract}

Keywords: Blood lactate, Recovery, recovery programme

\section{Introduction}

Mechanism of loading in sports training involves application of load as well as recovery process. In fact loading and recovery are considered to be two important aspects of the same unit- training load. Therefore these two processes have been studied and analyzed for understanding their functioning. A sufficient number of research works have conducted to analyze the aspect of loading. On the other hand there are not many investigations to analyze and understand the recovery process.

Recovery from exercise or training is an integral component of the overall training program and is essential for optimal performance and improvement. If the rate of recovery is improved, higher training volumes and intensities are possible without the detrimental effects of overtraining (Bishop et al., 2008). As recovery from exercise is significant, personal trainers and coaches use different approaches for the recovery process for clients and athletes. Understanding the physiological concept of recovery is essential for designing optimal training programmes. As well, individual variability exists within the recovery process due to training status (trained vs. untrained), factors of fatigue, and a person's ability to deal with physical, emotional, and psychological stressors (Jeffreys, 2005).

By recovery we understand the process of coming back to the normal state of physiological functioning after being disturbed with training load due to participation in games and sports or exercise. Physiologically the process of recovery has been effectively measured using different tests like recovery pulse testing. There are different conventional recovery programmes used by sports trainees. Some of them are complete rest, massage, cryotherapy, hydrotherapy, thermotherapy, contrast therapy, nonsteroidal antiinflammatory drugs, compression garments, stretching, progressive muscle relaxation technique, autogenic relaxation technique, and dietary interventions. It is also possible that combination of recovery interventions offer the most effective recovery benefits to the athlete. For example Monedero and Donne (2000) demonstrated significantly greater rates of recovery when athletes performed a combination of active recovery techniques, followed by massage, compared with only one recovery technique.

\section{Methodology}

Sixty intervarsity level males from Punjabi University, Patiala, voluntarily participated in the study. The subjects were divided into four equal experimental groups i.e, (i)Stretching exercise (ii)Slow cycling group (iii)Autogenic relaxation technique group and (iv)Progressive muscle relaxation group. All subjects were informed about the procedure, purpose of the study, any known risks and the right to terminate participation at will. Everyone expressed understanding by signing a statement of informed consent.

\section{Experimental Protocol}

Prior to testing sessions, subjects were familiared with the entire training by instruction and demonstration. The experimental groups underwent different recovery programmes. All the subjects were instructed to avoid caffeine and alcohol during the evaluation period and not to take heavy food at least 2 hours before the test and not to perform strenuous exercise at least 24 hours prior each session.

\section{Criterion measure}

The criterion measure adopted for the present study was blood lactate which was measured in $\mathrm{mmol} / \mathrm{l}$.

\section{Recovery Interventions}

\section{Stretching exercise}

The conditioning hall was set up with four cones forming the exercise area (10 meter long and 5 meters wide). Participants undertook the several exercises covering respective distance. 


\section{International Journal of Science and Research (IJSR) \\ ISSN (Online): 2319-7064}

Index Copernicus Value (2013): 6.14 | Impact Factor (2015): 6.391

Table 1: Stretching exercises module

\begin{tabular}{|c|c|c|}
\hline S No & Stretching Exercise & Distance covered \\
\hline 1 & $\begin{array}{c}\text { Knee to chest } \\
\text { Knee to chest }\end{array}$ & $\begin{array}{c}20 \text { meters } \\
20 \text { meters }\end{array}$ \\
\hline 2 & Hamstring kick out & 20 meters \\
\hline 3 & Frankenstein & 40 meters \\
\hline 4 & Quad Stretch & 20 meters \\
& Quad Stretch with heel raise & 20 meters \\
\hline 5 & Lunge & 20 meters \\
& Lunge with heel raise & 40 meters \\
\hline 6 & Lunge with tuck & 40 meters \\
\hline 7 & The Helicopter & 40 meters \\
\hline 8 & Side Lunge & 20 meters \\
\hline 9 & Spiderman & 40 meters \\
\hline 10 & Inchworm & 40 meters \\
\hline
\end{tabular}

\section{Slow cycling}

The participants completed 20 minutes of cycling on the Monark cycle Ergometer pedalling at $50 \mathrm{rpm}$ without any load.

\section{Autogenic relaxation technique}

During this recovery technique, the participants were seated in a comfortable position. With the help of experts this technique was practiced. They were asked to close their eyes and concentrate on their breathing and follow the commands for visualization. The practitioner repeated a set of visualizations that induce a state of relaxation.

\section{Progressive muscle relaxation}

Progressive muscle relaxation involved a two-step process in which muscle groups in the body systematically tense and relax different. Participants performed this technique by lying down in a comfortable position. With the eyes closed, the muscles were tensed (10 seconds) and relaxed (20 seconds) sequentially through various parts of the body.

The sequence runs as follows:

Table 2: Progressive muscle relaxation module

\begin{tabular}{|c|c|c|}
\hline 1. Right foot & 6. Left thigh & 11. Right arm and hand \\
\hline 2. Left foot & 7. Hips and buttocks & 12. Left arm and hand \\
\hline 3. Right calf & 8. Stomach & 13. Neck and shoulders \\
\hline 4. Left calf & 9. Chest & 14. Face \\
\hline 5. Right thigh & 10. Back & \\
\hline
\end{tabular}

\section{Testing Procedure}

Exercise test was performed on an electronically operated computerized bicycle ergometer using a test protocol that consisted of graded cycle ergometer. The subjects were asked to warm up and cycle at $60 \mathrm{RPM}$ for 2 minutes without any load. This constituted the initial/ reference phase. The test phase followed next. The initial load in the test phase was fixed at 50 watts, and increased by 50 watts every 2 min till exhaustion. For lactic acid measurements, blood samples were drawn from the finger tips using a lancet into strip and the value of lactic acid was automatically calculated with the help of portable lactate analyser. Soon after working on the bicycle ergometer the subjects were provided with the recovery programmes. Finally the posttest was conducted after 21 days to observe the significant difference on the said variables. The data for blood lactate was collected before exercise, after exercise and after the recovery programme on day one and on $21^{\text {st }}$ day of recovery programme. The duration of a day's recovery intervention was of 20 minutes.

\section{Statistics Procedure}

Statistical procedure was performed using SPSS version 20. Descriptive statistics were computed for all measures assessed, to test the normality Shapiro-Wilk test were done. Univariate technique Analysis of Covariance (ANCOVA) was applied to the data set to find out the effect of independent variables on recovery pattern of sportsperson. The level of significance for this study was fixed at 0.05 levels.

\section{Result and Discussions}

Table 3 Indicates the values of descriptive statistics (Mean, standard deviation, Standard error of mean and coefficient of variation) of the data measured in the pre and post testing of the treatment groups (Stretching Exercise, Slow Cycling, Autogenic Relaxation and Progressive Muscle Relaxation) of blood lactate.

Table 3: Descriptive statistics of the scores of Blood Lactate recovery after applying selected Experimental Conditions

\begin{tabular}{|c|c|c|c|c|}
\hline Experimental conditions & Mean & $\begin{array}{c}\text { Std. } \\
\text { Deviation }\end{array}$ & $\begin{array}{c}\text { Std. } \\
\text { Error }\end{array}$ & C.V.\% \\
\hline Stretching Exercise Pre & 7.58 & 1.37 & 0.35 & 18.07 \\
\hline Stretching Exercise Post & 4.55 & 0.77 & 0.20 & 16.92 \\
\hline Slow Cycling Pre & 10.65 & 2.50 & 0.64 & 23.47 \\
\hline Slow Cycling Post & 8.50 & 2.54 & 0.66 & 29.88 \\
\hline Autogenic Relaxation Pre & 12.31 & 1.28 & 0.33 & 10.40 \\
\hline Autogenic Relaxation Post & 10.61 & 0.93 & 0.24 & 8.77 \\
\hline $\begin{array}{c}\text { Progressive Muscle } \\
\text { Relaxation Pre }\end{array}$ & 12.27 & 3.18 & 0.82 & 25.92 \\
\hline $\begin{array}{c}\text { Progressive Muscle } \\
\text { Relaxation Post }\end{array}$ & 10.54 & 2.82 & 0.73 & 26.76 \\
\hline \multicolumn{1}{|c|}{} & & & \\
\hline
\end{tabular}

Shapiro-Wilk test was employed to check whether the assumption of normality of data was fulfilled or not. The calculated p-value of all the situations were more than 0.05 , they all were not significant at 0.05 level of significance. Thus the assumption of normality of data holds true in all the situations.

Table 4: Descriptive statistics of the on Blood lactate data measured in the Post testing after adjustment with the initial difference

\begin{tabular}{|c|c|c|c|c|}
\hline \multicolumn{5}{|c|}{ Dependent Variable: Post Lactate } \\
\hline Treatment Groups & Mean & $\begin{array}{c}\text { Std. } \\
\text { Error }\end{array}$ & \multicolumn{2}{|c|}{$\begin{array}{r}\text { 95\% Confidence } \\
\text { Interval }\end{array}$} \\
\cline { 4 - 5 } & & $\begin{array}{c}\text { Lower } \\
\text { Bound }\end{array}$ & $\begin{array}{c}\text { Upper } \\
\text { Bound }\end{array}$ \\
\hline Stretching Exercise & $7.02^{\mathrm{a}}$ & 0.30 & 6.42 & 7.61 \\
\hline Slow Cycling & $8.54^{\mathrm{a}}$ & 0.24 & 8.06 & 9.02 \\
\hline Autogenic Relaxation & $9.35^{\mathrm{a}}$ & 0.26 & 8.83 & 9.86 \\
\hline $\begin{array}{c}\text { Progressive Muscle } \\
\text { Relaxation }\end{array}$ & $9.30^{\mathrm{a}}$ & 0.26 & 8.79 & 9.81 \\
\hline Covalation & & & & \\
\hline
\end{tabular}

a. Covariates appearing in the model are evaluated at the following values: Pre Lactate $=10.7033$.

Table 4 indicates the estimates for overall Stretching Exercise recovery treatment, overall Slow Cycling recovery treatment, overall Autogenic Relaxation recovery treatment and overall Progressive Muscle Relaxation recovery 


\section{International Journal of Science and Research (IJSR) \\ ISSN (Online): 2319-7064 \\ Index Copernicus Value (2013): 6.14 | Impact Factor (2015): 6.391}

treatment of blood lactate irrespective of reading durations. These values are different from that of the unadjusted values (post lactate) shown in Table 3 . The advantage of using the ANCOVA is that the differences in the post-testing mean are compensated for the initial difference in the score. In other words, it may be said that the effect of covariate is eliminated in comparing the effectiveness of the treatment groups during post-testing.

Table 5: ANCOVA table for the Post hoc-test data on Blood Lactate

\begin{tabular}{|c|c|c|c|c|c|}
\hline \multicolumn{7}{|c|}{ Dependent Variable: Post Lactate } \\
\hline Source & $\begin{array}{c}\text { Type III Sum } \\
\text { of Squares }\end{array}$ & df & $\begin{array}{c}\text { Mean } \\
\text { Square }\end{array}$ & F & P-value \\
\hline Pre_lac & 173.98 & 1 & 173.98 & 201.22 & .000 \\
\hline Treatment & 29.50 & 3 & 9.83 & 11.37 & .000 \\
\hline Error & 47.55 & 55 & 0.87 & & \\
\hline
\end{tabular}

Table 5, Indicates the values test of difference between the subjects effects, which shows that there was a significant difference in pre test values of Blood Lactate for the four selected treatment groups, as the value was found to be 201.22 (Blood Lactate). Also, a significant difference was found between the post test values of the treatment groups as the value was found to be 11.37 (Blood Lactate) which was significant at 0.05 level. It shows the F-value for comparing the adjusted means of the treatment groups (Stretching Exercise, Slow Cycling, Autogenic Relaxation and Progressive Muscle Relaxation) during post-testing. Since pvalue for the F-statistic is 0.00 which is less than 0.05 , so of it is significant. Thus, the null hypothesis of no difference among the adjusted post-mean for the data on blood lactate in treatment groups may be rejected at $5 \%$ level. Since the Fratio in the above mentioned table is significant, a pair-wise comparison among different groups after Bonferroni adjustment for confidence interval was done.

Table 6: Post Hoc comparison for the group means in posttreatment adjusted with the initial differences

\begin{tabular}{|c|c|c|c|c|}
\hline & \multicolumn{4}{|c|}{ Dependent Variable: Post Lactate } \\
\hline $\begin{array}{c}\text { (I) } \\
\text { Treatment } \\
\text { Groups }\end{array}$ & (J) Treatment Groups & $\begin{array}{c}\text { Mean } \\
\text { Difference } \\
(\mathrm{I}-\mathrm{J})\end{array}$ & $\begin{array}{l}\text { Std. } \\
\text { Error }\end{array}$ & $\begin{array}{c}\text { P- } \\
\text { value. }\end{array}$ \\
\hline \multirow{3}{*}{$\begin{array}{l}\text { Stretching } \\
\text { Exercise }\end{array}$} & Slow Cycling & $-1.52^{*}$ & 0.38 & 0.00 \\
\hline & $\begin{array}{l}\text { Autogenic } \\
\text { Relaxation }\end{array}$ & $-2.33^{*}$ & 0.43 & 0.00 \\
\hline & $\begin{array}{l}\text { Progressive Muscle } \\
\text { Relaxation }\end{array}$ & $-2.28^{*}$ & 0.43 & 0.00 \\
\hline \multirow{3}{*}{$\begin{array}{c}\text { Slow } \\
\text { Cycling }\end{array}$} & Stretching Exercise & $1.52^{*}$ & 0.38 & 0.00 \\
\hline & $\begin{array}{l}\text { Autogenic } \\
\text { Relaxation } \\
\end{array}$ & -0.81 & 0.35 & 0.16 \\
\hline & $\begin{array}{l}\text { Progressive Muscle } \\
\text { Relaxation }\end{array}$ & -0.76 & 0.35 & 0.21 \\
\hline \multirow{3}{*}{$\begin{array}{l}\text { Autogenic } \\
\text { Relaxation }\end{array}$} & Stretching Exercise & $2.33^{*}$ & 0.43 & 0.00 \\
\hline & Slow Cycling & 0.81 & 0.35 & 0.16 \\
\hline & $\begin{array}{l}\text { Progressive Muscle } \\
\text { Relaxation }\end{array}$ & 0.05 & 0.34 & 1.00 \\
\hline \multirow{4}{*}{$\begin{array}{l}\text { Progressive } \\
\text { Muscle } \\
\text { Relaxation }\end{array}$} & Stretching Exercise & $2.28^{*}$ & 0.43 & 0.00 \\
\hline & Slow Cycling & 0.76 & 0.35 & 0.21 \\
\hline & Autogenic Relaxation & -0.05 & 0.34 & 1.00 \\
\hline & \multicolumn{4}{|c|}{$\begin{array}{c}\text { *The mean difference is significant at the } .05 \\
\text { level. }\end{array}$} \\
\hline
\end{tabular}

Table 6 shows the Post Hoc comparison for the group means in post-treatment adjusted with the initial differences. After the Pair wise comparison of Blood lactate at different treatments it was observed that there was a significant difference between Blood Lactate recoveries between Stretching Exercise group and Slow Cycling group as the value was found to be -1.52 , Stretching Exercise group and Autogenic Relaxation group as the value was found to be 2.33 \& Stretching Exercise group and Progressive Muscle Relaxation group as the value was found to be -2.28 , p-value for the mean difference between Stretching Exercise group and Slow Cycling group, Stretching Exercise group and Autogenic Relaxation group, Stretching Exercise group and Progressive Muscle Relaxation group is 0.00 as the P-value is less than 0.05 , which was significant at 0.05 level. Most of the possible combinations as the P-values of these combinations were less than 0.05. The three exceptional pairs with P-value more than 0.05 which exhibits insignificant difference were Slow Cycling group to Autogenic Relaxation group, Slow Cycling group to Progressive Muscle Relaxation group, and Autogenic Relaxation group and Progressive Muscle Relaxation group. Hence, it may be inferred that to control blood lactate all the treatments proved to be effective as among all the Groups after treatment blood lactic acid has shown downwards trends but Stretching Exercise group was most effective as difference between Pre and Post test was 3.03.

The aim of the present study was to compare lactate removal after different recovery intervention after a similar exercise in male adults. The effect of active recovery on lactate removal under different exercise conditions have been previously reported [Franchini et al.(2003), Spierer et al.(2004), Tessitore et al.(2007)]. Kinugusa \& Kilding(2009) observed positive effects on perceived recovery(higher quality of recovery and lighter legs) after the combination modality (cold water immersion and active recovery). Signorile et al.(1993) indicated that active recovery provides superior performance to passive rest in repeated short-term, high intensity power activities. Weltman et al.(1979) studied performance after a 1-minute all-out cycle ergometry effort, followed by 20 minutes of active recovery or rest period. Active recovery produced higher pedal revolutions in repeated bouts, accompanied by increased lactate removal rates. In the present study, differences between the blood lactate removals under different conditions were found to be significant. The results of the current investigation are in agreement with these previous studies.

\section{Conclusion}

The main finding of the present study was that blood lactate removal after an exercise with stretching exercises was more effective when compared with slow cycling, autogenic relaxation and progressive muscle relaxation. These results indicate stretching exercises may be an effective way for sportsperson to recover between consecutive training sessions and even during periodized training plan.

\section{References}

[1] Bishop, P.A, Jones E., \& Woods A.K, "Recovery from Training: a brief review," Journal of Strength and Conditioning Research, 22(3):1015-1024, 2008. 


\section{International Journal of Science and Research (IJSR) \\ ISSN (Online): 2319-7064}

Index Copernicus Value (2013): 6.14 | Impact Factor (2015): 6.391

[2] Franchini E, Yuri Takito M, Yuzo Nakamura F, Ayumi Matsushigue K, Peduti Dal'Molin Kiss MA, "Effects of Recovery type after a Judo combat on Blood Lactate Removal and on Performance in an intermittent task," Journal of Sports Medicine and Physical Fitness, 43(4): 424-31, 2003.

[3] Jeffreys, I, "A multidimensional approach to enhancing recovery," Strength and Conditioning Journal. 27(5): 7885, 2005.

[4] Kinugasa T., and Kilding AE, "A Comparison of PostMatch Recovery Strategies in Youth Soccer players", Journal of Strength and Conditioning Research, 23 (5), 1402-1407, 2009.

[5] Signorile FJ, Ingalls C, Tremblay LM, "The Effects of Active and Passive Recovery on Short-Term, High Intensity power output," Canadian Journal of Applied Physiology, 18(1), 31-42, 1993.

[6] Spierer DK, Goldsmith R, Baran DA, Hryniewicz K, Katz SD, "Effect of Active versus Passive Recovery on Work performed during serial supramaximal exercise tests", International Journal of Sports Medicine, 25(2), 109-14, 2004.

[7] Tessitore A, Meeusen R, Cortis C, Capranica L, "Effects of different Recovery interventions on Anaerobic Performances following preseason soccer training," The Journal of Strength \& Conditioning Research, 21(3): 745-50, 2007.

[8] Weltman A, Stamford BA, Fulco C, "Recovery from Maximal Effort Exercise: Lactate disappearance and Subsequent Performance", Journal of Applied Physiology: Respiratory Environmental and Exercise Physiology, 47(4), 677-82, 1979.

[9] Verma, J.P, Statistical Methods for Sports and Physical Education, Tata Mcgraw Hill Education Private Limited, New Delhi, 2011. 